\title{
Efficacy and Usability of an E-Learning Program for Fostering Qualified Disease Management Nurses
}

\author{
Kana Kazawa1, Michiko Moriyama1, Michiyo Oka², Satsuki Takahashi³, Madoka Kawai4, \\ Masumi Nakano 5 \\ ${ }^{1}$ Chronic Disease Management Project Research Center, Institute of Biomedical and Health Sciences, Hiroshima \\ University, Hiroshima, Japan \\ ${ }^{2}$ Graduate School of Health Sciences, Gunma University, Gunma, Japan \\ ${ }^{3}$ School of Nursing, Gunma Prefectural College of Health Sciences, Gunma, Japan \\ ${ }^{4}$ Division of Nursing Science, Institute of Biomedical and Health Sciences, Hiroshima University, Hiroshima, \\ Japan \\ ${ }^{5}$ Hiroshima City Asa Hospital, Hiroshima, Japan \\ Email: kkazawa@hiroshima-u.ac.jp
}

Received 22 July 2015; accepted 10 August 2015; published 13 August 2015

Copyright (C) 2015 by authors and Scientific Research Publishing Inc.

This work is licensed under the Creative Commons Attribution International License (CC BY). http://creativecommons.org/licenses/by/4.0/

\section{(c) (i) Open Access}

\section{Abstract}

In order to train nurses to perform disease management and telenursing, we developed an elearning education program, and assessed the efficacy. A single-group pre-test and post-test design was used. Nurses who worked at a medical institution or a disease management company were included, and the duration of the program was set 2 months. We developed the program so that it could grow attitude and improve knowledge and skills in disease management and patient education. Of 55 subjects, 48 who completed the program were analyzed. After the program, subjects increased knowledge and interests in disease management and patient education. Almost of the subjects answered that e-learning was a good learning method. Our program was effective at enhancing subject's interests in disease management and patient education, and considered to improve their skills in the future.

\section{Keywords}

\section{E-Learning, Education Program, Disease Management, Telenursing}




\section{Introduction}

With the change of disease composition, the healthcare system in the world has been required to change the targets from infectious diseases to non-infectious diseases (chronic diseases). However, since the structural reform has not caught up the change, there are unmet needs for chronic disease care, resulting in disease worsening and medical expense increase [1]-[3]. The situation is the same in Japan, and to solve this problem, in 2013, the government obligated all health insurers to carry out a data-health project aimed at improving health in their insured people and keeping reasonable medical expense [4]. Before this motion, we put into practice a new model that provided chronic disease care based on the disease management methodology in Japan. These programs were effective at preventing disease progression in patients with chronic illnesses and may contribute to the containment of medical costs [5]-[11]. Disease management was an outcome management method that was proposed early by the Disease Management Association of America, in order to properly allocate limited medical resources and provide high-quality healthcare with containing medical expense [12]. Disease management includes the following factors: 1) identification of a target population, 2) provision of standardized medical treatment and patient education based on evidence-based clinical practice guidelines, 3) interprofessional collaboration, 4) analysis and evaluation of outcomes and processes, 5) feedback to health care professionals and patients [13]. In disease management, we considered that nurses were the best players because they were good at arranging with professionals and services and specialized for patient education. Therefore, we have fostered disease management nurses (DM nurses) who perform disease management. Furthermore, we also considered that in order to provide care widely, the nurses should obtain the ability of practical telenursing that allowed them to communicate with people in remote areas and contain healthcare expense. Therefore, we set up a program for fostering disease management nurses using electronic learning (e-learning) on disease management and patient education for patients with a chronic disease (e-education for DM nurses). We developed our program using e-learning, because we considered that e-learning could be a good way for nurses to learn at their own pace at workplace or home and that it could ensure the number of disease management nurses nationwide and guarantee their quality. Regarding the efficacy of e-learning for students, several articles reporting e-learning education used in nurse training faculties and they mentioned that e-learning was not inferior to the traditional face-to-face education in improving subject's knowledge and their practical ability as well as their satisfaction [14] [15]. Also, for the registered nurses, there are many articles reporting that education using e-learning resulted in improvement of subject's knowledge and skills [16]-[18]. These reports used themes such as diseases and nursing skills, and there has been no study on the theme of acquiring comprehensive ability including disease management and patient education. In addition, although it has been reported that patient education that is structured based on theories and evidences can improve outcome [19]. However, no study has shown the process of developing e-learning on improving the ability of patient education, and incorporated theories.

Therefore, in this study, we developed the e-learning education program on nurses who implemented disease management in order to foster comprehensive ability integrating knowledge and skills of disease management, patient education, and behavior modification. Then, we assessed the efficacy and the operability. If we can assure the quality of disease management nurses above a certain standard, it would guarantee the quality of disease management project in Japan.

\section{E-Education for DM Nurses}

\subsection{Program Structure, Themes, and Goal Setting}

The program structure is shown in Figure 1. Based on the classification of educational objectives proposed by Bloom et al. [20], we incorporated three dimensions of attitude, knowledge and phsychomotor skills as the frameworks. The goal of our program was to "train generalist nurses to perform chronic disease management and telenursing" and generalist nurses were defined as nurses who had graduated from a basic nursing education course (professional school or university undergraduate education) and had clinical experience.

For the program structure, we selected outlines of disease management (including health assessment/nursing process), knowledge about characteristics of chronic diseases that are keys for disease management, care coordination, communication and quality management as the 5 themes. As "disease management", we included items such as definition and structure of disease management, program-developing process, evidence based medicine, patient education (including cognitive behavior therapy), and care triangulation (Emic: subjective 


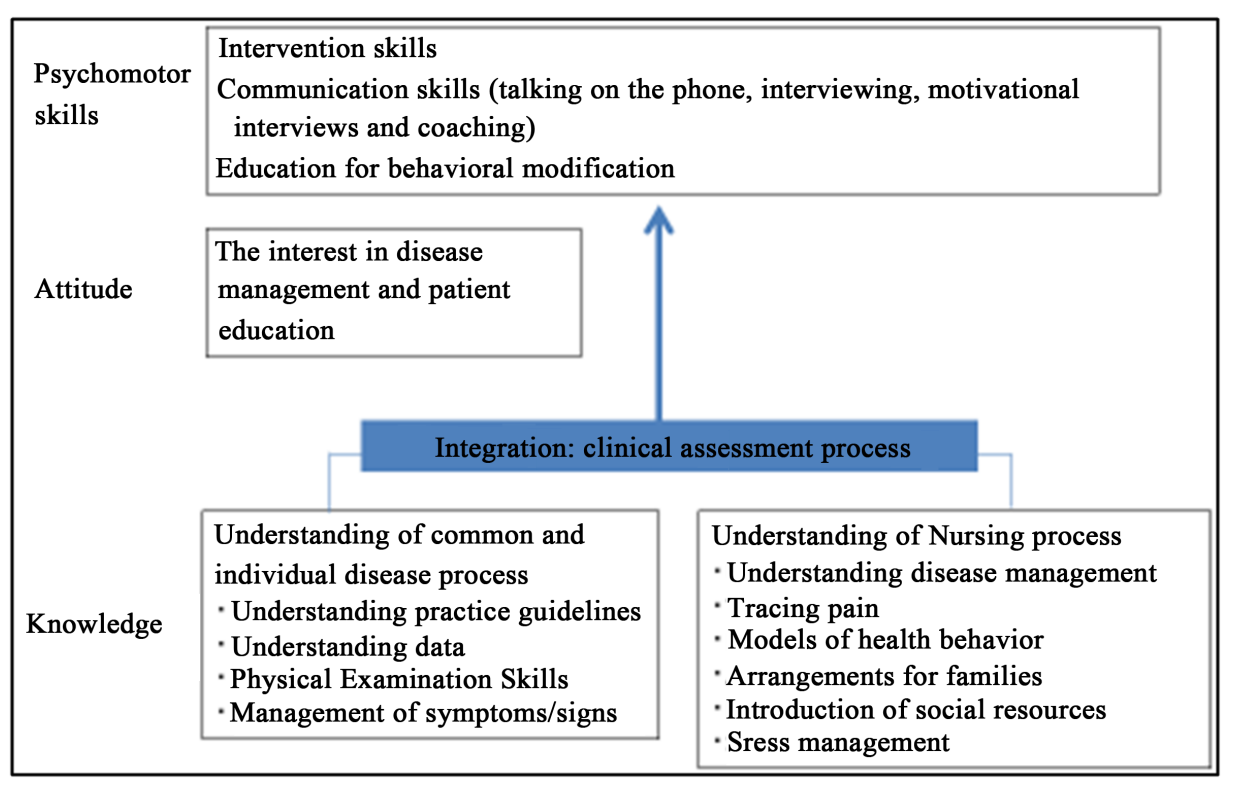

Figure 1. The structure of education program.

approach taking into account Illness Narrative and Etic: objective approach taking into account data based on evidence). For the developing process, we built it up to follow the same course as nursing process that goes thorough comprehensive health assessment on patient's disease and risk factors from the physical, mental and social aspects, intervention, evaluation and feedback. For "knowledge of disease characteristics", we included diseases with a high incidence, i.e. metabolic syndrome, diabetes, diabetic nephropathy, ischemic heart disease, heart failure and stroke, and constructed the contents for the disease, diagnosis, standard treatment, medical care management and management goals and patient education, based on practice guidelines [21]-[25]. Furthermore, we included detailed contents to support acquiring self-management skills. For "care coordination", we defined that it was to assess needs of medical resources, support the patient and their family's decision making, and coordinate multidisciplinary collaboration. Therefore, in addition to skill of stratification, we educated on methods to assess medical resources and create medical and local collaboration, methods and skills of care coordination, and methods to support families as a care unit. For "communication”, we educated on skills required for patient education, communication with physicians and telenursing. As skills required for patient education, the motivation interview methods, coaching, cognitive behavior therapy and behavior change skills were included [26] [27]. For "quality management", knowledge and skills required as research nurses (mainly, data monitoring, data management and personal data protection) and utilization of IT systems were included. Finally, as a summary of these lectures, we used videos illustrating physical examination and patient education techniques, such as the techniques for actual interviewing and telenursing (role play with simulated patients), for motivation interview methods, for management of diseases.

\subsection{Development of E-Learning}

Characteristically, e-learning is a way to learn subjectively, individually and repeatedly at learner's own pace, with enjoyment and easy understanding using senses of vision and hearing as well as a way to acquire the decision-making ability by following thinking process of experts in special fields [28]. We prepared lectures of 20 to 80 minutes for each theme and if the duration was longer than 20 minute, we divided it by 20 minutes, so that subjects could learn easily and repeatedly at their own pace.

For each theme, physicians and nurses specialized in the field, nurses specialized for managing chronic diseases, nurses certified for motivation interview, specialists for behavior change, physical therapists for exercise therapy and nutritionists for diet therapy performed the lecture. In the part of role play, nurses specialized for chronic disease management actually demonstrated. The screen layout of e-learning consisted of movies showing teachers giving their lecture and learning materials simultaneously. 


\subsection{Evaluation Tests}

For individual themes, we set 10 yes-no questions based on the lecture to evaluate acquisition levels of learning.

\section{Methods}

\subsection{Subjects}

Nurses who worked at an acute-care hospital or a disease management company, and agreed to participate in the study. Clinical experience should be at least 3 years and those who were during the postpartum period or the childcare leave could be included. We did not consider the specialized area of working and the level of basic education (university (undergraduate, graduate) or professional school). Exclusion criteria were assistant nurses, midwifes, nurses in manager positions (director of nursing, assistant director, ward manager).

\subsection{Period of Analysis}

April-December, 2014.

\subsection{Research Design}

A single-group pre-test and post-test design was used.

\subsection{Primary and Secondary Endpoint}

Evaluation indicators were set with reference to the classification of education targets [20]. In the classification, it is considered that most behaviors that arise from learning results involve 3 domains, i.e. "the cognitive domain" associated with acquiring knowledge, understanding and developing intellectual abilities, "the emotional domain” associated with developing interests, attitude and sense of value as well as emotion, proper judgment and adaptability, and "the psychomotor domain" associated with technical skills and motor skills. In addition, it is also considered that the emotional domain is corresponding to results from developing the cognitive domain. Based on this, learning effects were measured for the 3 domains, while we operationally defined the cognitive domain as "subjective evaluation on acquiring knowledge about disease management/patient education”, the emotional domain as "interests in disease management and patient education" and the psychomotor domain as "acquiring skills in patient education” and used them as primary endpoints for education effects. The scales to measure achieved level of each domain were prepared as follows by researchers using Likert scale (Table 1).

Secondary endpoints were test scores evaluating acquired knowledge of each e-learning theme. For each subject, the average score was calculated for each theme.

In addition, for the program operability, subjects were asked to evaluate 1) the duration of e-learning (20minutes sessions), 2) the numbers of themes and subthemes, 3) easiness of taking the program, 4) acceptance as a learning tool, in likert scale of 3 or 4 grades and also they could comment voluntary for the items.

\subsection{Data Collection}

Scores for the emotional domain, the cognitive domain and e-learning tests were obtained from subjects. The score for the psychomotor domain was obtained by research assistants who evaluated skills of subjects performing patient education on an actual setting. The research assistants only performed the evaluation and were not involved in analysis. As the schedule for data collection, scores for the emotional domain and the cognitive domain were collected at 2 time points before and after the program. Because we considered that it needed a lot of time to learn skills for disease management and patient education, scores for the psychomotor domain were collected at 1 time point after the program. Scores of e-learning tests were obtained when the subjects answered tests before and after completing each theme. Evaluation of the program was obtained at the end of the program.

\subsection{Recruitment and Registration Procedures}

Nurse managers who agreed to support this study introduced nurses who met the eligibility criteria. The researchers explained them about the objectives and contents of this program orally and in written form, after that obtained a written consent. 
Table 1. Scales for evaluation of the emotional/cognitive/psychomotor domains.

\begin{tabular}{|c|c|c|c|c|}
\hline Domain & Item & Point & $\begin{array}{l}\text { Item } \\
\text { number }\end{array}$ & $\begin{array}{l}\text { Score } \\
\text { range }\end{array}$ \\
\hline \multirow{5}{*}{$\begin{array}{l}\text { Emotional } \\
\text { domain } \\
\text { (interest) }\end{array}$} & Interest in disease management & \multirow{5}{*}{$\begin{array}{l}\text { 1: not interested - } \\
\text { 4: interested }\end{array}$} & \multirow{5}{*}{5} & \multirow{5}{*}{$5-20$} \\
\hline & Challenges for disease management & & & \\
\hline & Disease management is a skill that helps my career as a nurse & & & \\
\hline & Education for noncompliant/non-adherent patients & & & \\
\hline & Confidence to change behavior of noncompliant/non-adherent patients & & & \\
\hline \multirow{13}{*}{$\begin{array}{c}\text { Cognitive } \\
\text { domain } \\
\text { (knowledge) }\end{array}$} & Disease management & \multirow{13}{*}{$\begin{array}{l}\text { 1: not understood - } \\
\text { 4: understood }\end{array}$} & \multirow{13}{*}{13} & \multirow{13}{*}{$13-52$} \\
\hline & How to apply evidence-based medicine to clinical practice & & & \\
\hline & Pathophysiology of diseases & & & \\
\hline & Treatments for diseases & & & \\
\hline & Examinations for diseases & & & \\
\hline & Self-management education & & & \\
\hline & Outline of care coordination & & & \\
\hline & Care coordination: stratification skills & & & \\
\hline & Care coordination: healthcare collaboration/local cooperation & & & \\
\hline & Care coordination: necessary healthcare resources & & & \\
\hline & Patient education & & & \\
\hline & Cognitive behavioral therapy/cognitive behavior theory & & & \\
\hline & Study method: study design, data management & & & \\
\hline \multirow{5}{*}{$\begin{array}{l}\text { Psychomotor } \\
\text { domain } \\
\text { (skills) }\end{array}$} & Health assessment (incl. physical examination): 18 items & \multirow{5}{*}{$\begin{array}{l}\text { 1: not achieved - } \\
\text { 4: achieved }\end{array}$} & \multirow{5}{*}{46} & \multirow{5}{*}{$46-184$} \\
\hline & Patient education in self-management for behavioral change: 11 items & & & \\
\hline & Tele-communication skills: 7 items & & & \\
\hline & Communication with physicians: 5 items & & & \\
\hline & Attitude and manner as a professional: 5 items & & & \\
\hline
\end{tabular}

\subsection{Program Implementation}

We gave URL of the e-learning education program to subjects who agreed, and explained how to take the program and that they should complete the program within about 2 months from the enrolled day. We also told that they could take the program at any time and any place they wanted. In addition, from the view point of protecting intellectual property, we obtained a written consent to promise proper handling of the program URL.

\subsection{Method of Analysis}

To compare indicators over time, we used the t-test or the Wilcoxon signed-rank test, and the significance level was set at $p<0.05$. Comments answered voluntarily were summarized inductively.

\subsection{Ethical Considerations}

Approval was obtained from the ethics committees of Hiroshima University. The researchers explained to subjects about the purpose of this study, learning content, data collection, confidentiality, how the results would be published, and that they would be free to withdraw. Subjects gave a written consent. 


\section{Results}

\subsection{Outlines of Subjects}

Among 55 nurses who agreed to participate in the study, 48 completed the e-education (the completion rate: 87.3\%). Seven nurses dropped out the e-education because they were too busy with their work or care giving.

As basic characteristics of subjects, there were 45 females (93.8\%) and 3 males (6.2\%), and 30 subjects (62.5\%) had graduated from a nursing school/a junior college (3-year course), 16 (33.3\%) had graduated from a 4-year college, while 2 completed a graduate school as their last academic record.

\subsection{Efficacy of E-Learning Program}

1) Changes in scores for cognitive domain and emotional domain/ scores for psychomotor domain

Changes in scores for the emotional and the cognitive domains over time and scores for the psychomotor domain are shown in Table 2 . Scores for the cognitive and the emotional domains were significantly increased after program $(p<0.01)$.

2) Changes in test scores for each theme of e-learning

Changes in scores for each e-learning theme before and after completing the theme are shown in Table 3. For all the items, scores were significantly increased after e-learning $(p<0.001)$. Especially, scores for knowledge about disease characteristics rose higher than else scores.

Table 2. Scores for the three domains.

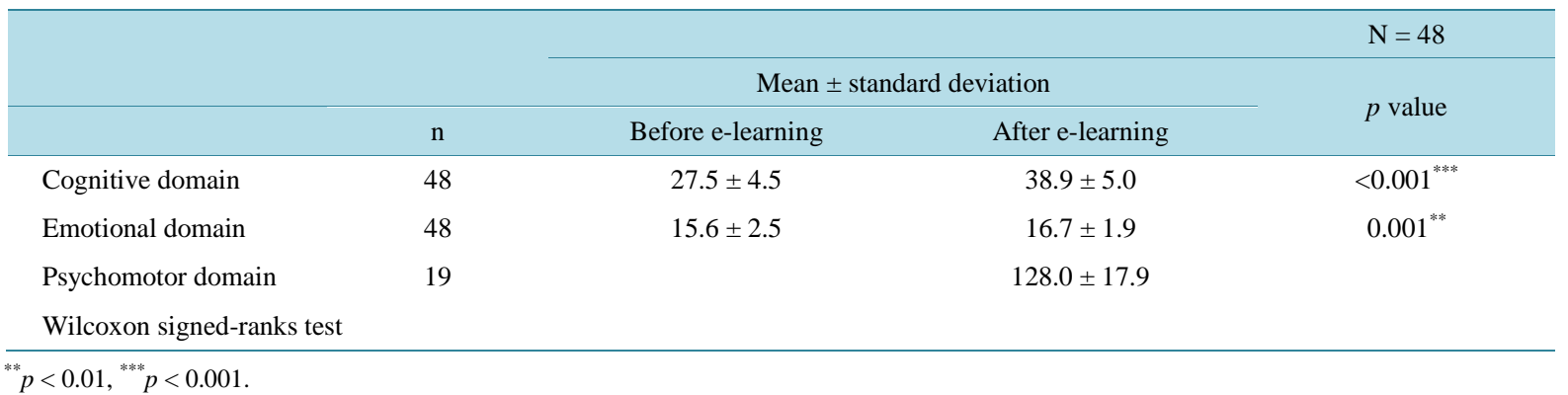

Table 3. Scores for each e-learning theme.

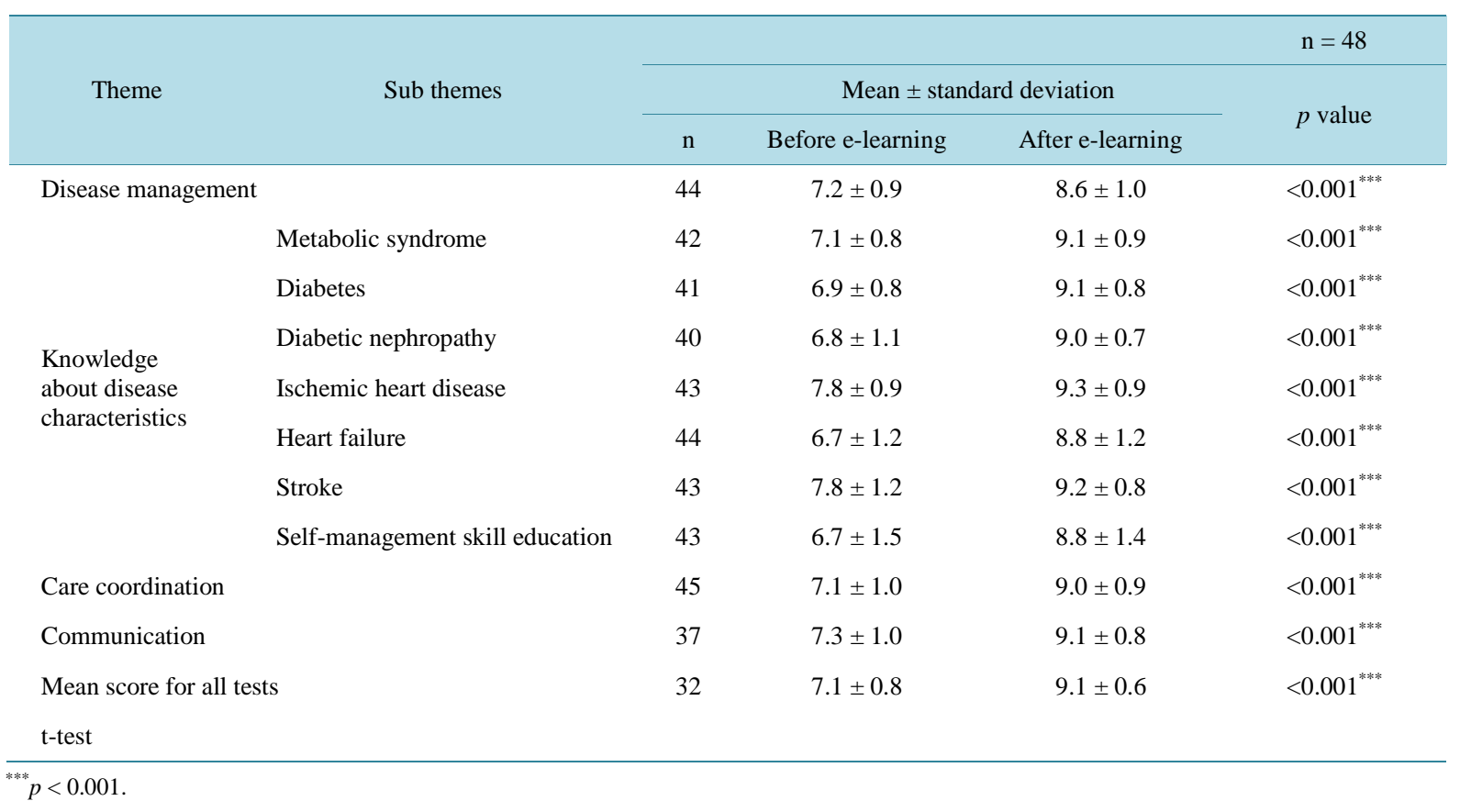




\subsection{Evaluation on Program Operability by Subjects}

Evaluations on the program operability by subjects are shown in Table 4. As a learning method, 47 subjects (97.9\%) rated e-learning as "good” or "relatively good”. Regarding the easiness of taking a course, 40 subjects (85.5\%) rated e-learning as "easy” or "relatively easy”. There were 7 subjects (14.6\%) who rated as "difficult to take” mainly because "it was difficult to write down contents and I wanted a text” or "I want to know my course record and past test results”.

Regarding the duration of e-learning, 25 subjects (52.1\%) rated as “appropriate” and other 22 (45.8\%) rated as "too long”. For the numbers of themes included in the e-learning, 14 subjects $(29.2 \%)$ rated as "appropriate" and 34 (70.8\%) rated as "too many". Those who replied that the duration of e-learning was "too long” or that the number of themes included in e-learning was "too many", also described "since the course was divided into short sessions, it was easy to focus on, but it is too hard to complete the all sessions within the term."

As voluntary comments, we had some distinctive answers, e.g. the learners said that they could repeatedly learn about disease management based on evidence, and they thought that they understood the processes of patient education and could utilize it in the practice.

\section{Discussion}

\subsection{Operability of Program}

Among the subjects, 97.9\% replied that e-learning was a good learning method, and 85.5\% replied that it was easy to take, which indicates a high evaluation for the program quality. In addition, the completion rate of the program was $87.3 \%$ and all subjects who stopped the program did so because they were too busy. In this study, taking into account the operability, we set the time frame at 2 months. However, since some subjects commented in program evaluation that they felt it as a burden to complete the whole program within the limited time, the operability may be improved if we set a longer time frame.

\subsection{Efficacy of Program}

Telenursing is a concept that was defined by the International Council of Nurses in 1998, and there have been various reports abroad and in Japan on improvement of disease management and containment of healthcare expenses by telenursing in patients with a chronic disease [29]-[33]. ICN states that the skill of telenursing is a tool to perform nursing process including assessment, diagnosis, planning, exercise and evaluation for patients, and that the ability to perform nursing process as well as development of partnership influence the quality of telenursing. In addition, in order to perform disease management, not only evidence-based patient education but also the abilities to support practice and collaborate with other professionals are required [34]. We developed our learning program to train and evaluate nurses so that they could acquire knowledge and skills related to them.

The subjects of our program increased scores of e-learning for the emotional domain (interests in disease management and patient education) and the cognitive domain (subjective evaluation on acquiring knowledge about disease management and patient education). Also, for the psychomotor domain (patient education skills),

\begin{tabular}{|c|c|c|c|c|}
\hline & & & & $\mathrm{N}=48 \mathrm{n}(\%)$ \\
\hline \multirow{2}{*}{$\begin{array}{c}\text { Overall view of } \\
\text { e-learning }\end{array}$} & Good & Relatively good & Not so good & Bad \\
\hline & $25(52.1)$ & 22 (45.8) & $1(2.1)$ & $0(0.0)$ \\
\hline \multirow{2}{*}{$\begin{array}{l}\text { Easiness of } \\
\text { e-learning }\end{array}$} & Easy & Relatively easy & Difficult & \\
\hline & 33 (68.8) & $8(16.7)$ & 7 (14.5) & \\
\hline \multirow{2}{*}{$\begin{array}{c}\text { Duration of } \\
\text { e-learning }\end{array}$} & Too long & Appropriate & Too short & \\
\hline & $22(45.8)$ & $25(52.1)$ & $1(2.1)$ & \\
\hline \multirow{2}{*}{$\begin{array}{l}\text { Themes included } \\
\text { in e-learning }\end{array}$} & Too many & Appropriate & Too few & \\
\hline & 34 (70.8) & $14(29.2)$ & $0(0.0)$ & \\
\hline
\end{tabular}


we set items that could evaluate skills required for face-to-face and telenursing patient education. However, the evaluation for the psychomotor domain was made only after the program. Although there is the limitation of the study, we consider that since we achieved our intended results, the program was structured appropriately.

Knowls stated that in adult learning, it is important to utilize their own experience as abundant learning resources and to show how to apply them in the practice [35]. Also, there were voluntary comments by subjects such as "I could learn by comparing with my actual experience" and "I would like to make good use in everyday practice", and these comments indicate that they could learn deeply using they own experience and that they could obtain some suggestion for the actual practice. Therefore, we consider that repeated learning using experience and contents along with thinking process of experts based on the practice were effective.

Furthermore, it has been reported that in chronic disease management, education to improve patient's ability of self-management is most effective in improving patient's outcome [19] [36], and it is essential for disease management. To understand how the intervention by nurses who enhanced their skills in patient education after our e-learning program could improve outcomes in patients with a chronic disease, it would be necessary to conduct further investigation.

\section{Limitations of the Study and Future Challenges}

As the design of our study, we performed tests before and after only in an intervened group and did not set a control group, because the nurse administrators of the facilities desired that all nursing staff needed to learn the skills. Also, the evaluation term was short with 2 months, but it is considered that in order to evaluate skill acquisition, a longer term for before-after evaluation and comparison was necessary. However, the positive result from this study suggests that further investigation with a controlled comparison and a longer-term evaluation may demonstrate more valuable results.

\section{Conclusion}

We carried out a nurse training program using e-learning on disease management and patient education, and it improved subject's knowledge and interests. We consider that knowledge enhancement through e-learning and learning along with the process of patient education can contribute to improvement of patient education skills.

\section{References}

[1] Barlow, J., Wright, C., Sheasby, J., Turner, A. and Hainsworth, J. (2002) Self-Management Approaches for People with Chronic Conditions: A Review. Patient Education and Counseling, 48, 177-187. http://dx.doi.org/10.1016/S0738-3991(02)00032-0

[2] Lozano, R., Naghavi, M., Foreman, K., et al. (2012) Global and Regional Mortality from 235 Causes of Death for 20 Age Groups in 1990 and 2010: A Systematic Analysis for the Global Burden of Disease Study 2010. Lancet, 380, 2095-2128. http://dx.doi.org/10.1016/S0140-6736(12)61728-0

[3] Suhrcke, M., Daragh, K.F. and McKee, M. (2008) Economic Aspects of Chronic Disease and Chronic Disease Management. In: Nolte, E. and Mckee, M.B., Eds., Caring for People with Chronic Conditions, Open University Press, England, 43-63.

[4] Ministry of Health, Labour and Welfare (2014) Promotion of Data-Health Project. (In Japanese) http://tokuteikenshin-hokensidou.jp/interview/002/datahealth_mhlw.pdf

[5] Fukuoka, Y., Hosomi, N., Hyakuta, T., Omori, T., Ito, Y., Uemura, J., Kimura, K., Matsumoto, M. and Moriyama, M., DMP Stroke Trial Investigators (2014) Baseline Feature of a Randomized Trial Assessing the Effects of Disease Management Programs for the Prevention of Recurrent Ischemic Stroke. Journal of Stroke and Cerebrovascular Diseases, 24, 610-617. http://dx.doi.org/10.1016/j.jstrokecerebrovasdis.2014.10.007

[6] Kazawa, K. and Moriyama, M. (2012) Effects of the Educational Program for Pre-Dialysis Patients with Diabetic Nephropathy (Intervention Evaluation for 6 Months). The Journal of Japan Academy of Nephrology Nursing, 14, 92100. (In Japanese)

[7] Kazawa, K. and Moriyama, M. (2013) Effects of a Self-Management Skills-Acquisition Program on Pre-Dialysis Patients with Diabetic Nephropathy. Nephrology Nursing Journal, 40, 141-149.

[8] Kazawa, K., Takeshita, Y., Yorioka, N. and Moriyama, M. (2014) Efficacy of a Disease Management Program Focused on Acquisition of Self-Management Skills in Pre-Dialysis Patients with Diabetic Nephropathy: 24 Months Follow-Up. Journal of Nephrology, 28, 329-338. http://dx.doi.org/10.1007/s40620-014-0144-2 
[9] Moriyama, M., Takeshita, Y., Haruta, Y., Hattori, N. and Ezenwaka, C.E. (2013) Effects of a 6-Month Nurse-Led Self-Management Program on Comprehensive Pulmonary Rehabilitation for Patients with COPD Receiving Home Oxygen Therapy. Rehabilitation Nursing, 40, 40-51. http://dx.doi.org/10.1002/rnj.119

[10] Otsu, H. and Moriyama, M. (2012) Follow-Up Study for a Disease Management Program for Chronic Heart Failure 24 Months after Program Commencement. Japan Journal of Nursing Science, 9, 136-148. http://dx.doi.org/10.1111/j.1742-7924.2011.00194.X

[11] Takami, C., Moriyama, M., Nakano, M., Kuroe, Y., Nin, K., Morikawa, H., Hasegawa, T. and Hayashi, S. (2008) Developmental Process of Disease Management Program of Type 2 Diabetes with a View to Acquiring Self-Management Skills: Effects of the Trial Implementation. Japan Journal of Nursing Science, 28, 59-68.

[12] Fitzner, K., Sidorov, J., Fetterolf, D., Wennberg, D., Eisenberg, E., Cousins, M., Hoffman, J., Haughton, J., Charlton, W., Krause, D., Woolf, A., McDonough, K., Todd, W., Fox, K., Plocher, D., Juster, I., Stiefel, M., Villagra, V. and Duncan, I. (2004) Principles for Assessing Disease Management Outcomes. Disease Management, 7, 191-201. http://dx.doi.org/10.1089/dis.2004.7.191

[13] Population Health Alliance (2014) PHM: Disease Management. http://www.populationhealthalliance.org/research/phm-glossary/d.html

[14] McCutcheon, K., Lohan, M., Traynor, M. and Martin, D. (2014) A Systematic Review Evaluating the Impact of Online or Blended Learning vs. Face-to-Face Learning of Clinical Skills in Undergraduate Nurse Education. Journal of Advanced Nursing, 71, 255-270. http://dx.doi.org/10.1111/jan.12509

[15] Segal, G., Balik, C., Hovav, B., Mayer, A., Rozani, V., Damary, I., Golan-Hadari, D., Kalishek, S. and Khaikin, R. (2013) Online Nephlorogy Course Replacing a Face to Face Course in Nursing Schools’ Bachelor’s Program: A Prospective, Controlled Trial, in Four Israeli Nursing Schools. Nurse Education Today, 33, 1587-1591. http://dx.doi.org/10.1016/j.nedt.2012.12.009

[16] Hart, P., Eaton, L., Buckner, M., Morrow, B.N., Barrett, D.T., Fraser, D.D., Hooks, D. and Sharrer, R.L. (2008) Effectiveness of a Computer-Based Educational Program on Nurses' Knowledge, Attitude, and Skill Level Related to Evidence-Based Practice. Worldviews on Evidence-Based Nursing, 5, 75-84. http://dx.doi.org/10.1111/j.1741-6787.2008.00123.x

[17] Moattari, M., Moosavinasab, E., Dabbaghmanesh, M.H. and ZarifSanaiey, N. (2014) Validating a Web-Based Diabetes Education Program in Continuing Nursing Education: Knowledge and Competency Change and User Perceptions on Usability and Quality. Journal of Diabetes \& Metabolic Disorders, 13, 70.

[18] Sheen, S.T.H., Chang, W.Y., Chen, H.L., Chao, H.L. and Tseng, C.P. (2008) E-Learning Education Program for Registered Nurses: The Experience of a Teaching Medical Center. Journal of Nursing Research, 16, 195-201. http://dx.doi.org/10.1097/01.JNR.0000387306.34741.70

[19] Funnell, M.M., Brown, T.L., Childs, B.P., Haas, L.B., Hosey, L.B., Jensen, B., Marynuik, M., Peyrot, M., Piette, J.D., Reader, D., Siminerio, L.M., Weinger, K. and Weiss, M.A. (2007) National Standards for Diabetes Self-Management Education. Diabetes Care, 30, 1630-1637. http://dx.doi.org/10.2337/dc07-9923

[20] Bloom, B.S., Hastings, J.T. and Madaus, G.F. (1971) Handbook on Formative and Summative Evaluation of Student Learning. McGraw-Hill Book Company, New York.

[21] Japanese Society of Nephrology (2013) Evidence-Based Practice Guideline for the Treatment of CKD. Tokyo Igakusha, Tokyo. (In Japanese)

[22] The Japan Diabetes Society (2013) Evidence-Based Practice Guideline for the Treatment for Diabetes in Japan 2013. Nankodo, Tokyo. (In Japanese)

[23] The Japanese Circulation Society (2010) Guidelines for Treatment of Chronic Heart Failure (JCS 2010). http://www.j-circ.or.jp/guideline/pdf/JCS2010_matsuzaki_h.pdf

[24] The Japanese Circulation Society (2011) Guidelines for Secondary Prevention of Myocardial Infarction (JCS 2011). (In Japanese) http://www.j-circ.or.jp/guideline/pdf/JCS2011_ogawah_h.pdf

[25] The Japan Stroke Society (2009) Japanese Guidelines for the Management of Stroke. Kyowa kikaku, Tokyo. (In Japanese)

[26] Bandura, A. (1977) Self-Efficacy: Toward a Unifying Theory of Behavioral Change. Psychological Review, 84, 191215. http://dx.doi.org/10.1037/0033-295X.84.2.191

[27] Prochaska, J.O. and Velicer, W.F. (1997) The Transtheoretical Model of Health Behavior Change. American Journal of Health Promotion, 12, 38-48. http://dx.doi.org/10.4278/0890-1171-12.1.38

[28] Morikawa, H., Nonomura, N. and Muranaka, Y. (2001) The Trends of Nursing with CAI and the State of Available Materials. Kangotenbo, 26, 68-75. (In Japanese)

[29] Dunagan, W.C., Littenberg, B., Ewald, G., Jones, C.A., Emery, V.B., Waterman, B.M., Silverman, D.C. and Rogers, 
J.G. (2005) Randomized Trial of a Nurse-Administered, Telephone-Based Disease Management Program for Patients with Heart Failure. Journal of Cardiac Failure, 11, 358-365. http://dx.doi.org/10.1016/j.cardfail.2004.12.004

[30] Jensen, L., Leeman-Castillo, B., Coronel, S.M., Perry, D., Belz, C., Kapral, C. and Krantz, M.J. (2009) Impact of a Nurse Telephone Intervention among High-Cardiovascular-Risk, Health Fair Participants. Journal of Cardiovascular Nursing, 24, 447-453. http://dx.doi.org/10.1097/jcn.0b013e3181b246d9

[31] Kamei, T., Yamamoto, Y., Kajii, F., Nakayama, Y. and Kawakami, C. (2013) Systematic Review and Meta-Analysis of Studies Involving Telephone Monitoring-Based Telenursing for Patients with Chronic Obstructive Pulmonary Disease. Japan Journal of Nursing Sciences, 10, 180-192. http://dx.doi.org/10.1111/j.1742-7924.2012.00228.x

[32] Kim, H.S. (2007) Impact of Web-Based Nurse's Education on Glycosylated Hemoglobin in Type 2 Diabetic Patients. Journal of Clinical Nursing, 16, 1361-1366. http://dx.doi.org/10.1111/j.1365-2702.2007.01506.x

[33] Shearer, N.B.C., Cisar, N. and Greenberg, E.A. (2007) A Telephone-Delivered Empowerment Intervention with Patients Diagnosed with Heart Failure. Heart \& Lung: The Journal of Acute and Critical Care, 36, 159-169. http://dx.doi.org/10.1016/j.hrtlng.2006.08.006

[34] Wagner, E.H. (2000) The Role of Patient Care Teams in Chronic Disease Management. British Medical Journal, 320, 569-572. http://dx.doi.org/10.1136/bmj.320.7234.569

[35] Knowls, M.S. (1988) The Modern Practice of Adult Education: From Pedagogy to Andragogy. Association Press, New York, 45-54.

[36] Nakano, M., Moriyama, M. and Nishiyama, M. (2003) Structured Review of the Literature of Type 2 Diabetes SelfManagement: Toward the Development of a Patients' Characteristics-Based Assessment Tool. Journal of Health Sciences, 3, 1-12. (In Japanese) 